\title{
Studies on the Effects of Certain Soil Properties on the Biodegradation of Oils Determined by the Manometric Respirometric Method
}

\author{
Juhani Kaakinen, ${ }^{1}$ Pekka Vähäoja, ${ }^{2}$ Toivo Kuokkanen, ${ }^{3}$ and Katri Roppola ${ }^{3}$ \\ ${ }^{1}$ North Ostrobothnia Regional Environment Centre, 90101 Oulu, Finland \\ ${ }^{2}$ Department of Mechanical Engineering, University of Oulu, 90014 Oulu, Finland \\ ${ }^{3}$ Department of Chemistry, University of Oulu, 90014 Oulu, Finland
}

Received 20 June 2007; Accepted 1 August 2007

\begin{abstract}
The biodegradability of certain biofuels was studied in the case of forest soils using the manometric respirometric technique, which was proved to be very suitable for untreated, fertilized as well as $\mathrm{pH}$ adjusted soils. Experiments carried out in infertile sandy forest soil gave a BOD/ThOD value of $45.1 \%$ for a typical model substance, that is, sodium benzoate after a period of 30 days and mineral addition improved the BOD/ThOD value to a value of 76.2\%. Rapeseed oil-based chain oil almost did not biodegrade at all in 30 days in nonprocessed soil, and when $\mathrm{pH}$ was adjusted to 8.0 , the BOD/ThOD value increased slightly to a value of $7.4 \%$. Mineral addition improved the BOD/ThOD value on average to $43.2 \%$ after 30 days. The combined mineral addition and $\mathrm{pH}$ adjustment together increased the BOD/ThOD value to $75.8 \%$ in 30 days. The observations were similar with a rapeseed oil-based lubricating oil: after 30 days, the BOD/ThOD value increased from 5.9\% to an average value of $51.9 \%$, when the $\mathrm{pH}$ and mineral concentrations of the soil were optimized. The mineral addition and $\mathrm{pH}$ adjustment also improved the precision of the measurements significantly.
\end{abstract}

Copyright (c) 2007 Juhani Kaakinen et al. This is an open access article distributed under the Creative Commons Attribution License, which permits unrestricted use, distribution, and reproduction in any medium, provided the original work is properly cited.

\section{INTRODUCTION}

In 2004, (Finland's environmental administration, Helsinki, Finland) was aware of more than 20,000 sites, in which the soil could be contaminated. Around 10,000 sites were located at less than 100 metres away from residential, groundwater, or surface water areas; or less than 200 metres away from a source of water supply, and were potentially contaminated. Some of these 10,000 sites may even pose several risks, due to the nature of the contamination. Many activities are known to cause soil contamination. Thus in urban areas, the need for a site investigation usually arises because of land use charges. It is also important to ensure groundwater protection in groundwater areas. Contamination of soils results in most cases from the careless use of chemicals, or simply out of disregard or ignorance. In Finland, typical activities or establishments that have caused contamination of soils have been fuel storage or distribution facilities, sawmills, impregnation plants, other various forms of industries, various depots, garages, greenhouses, as well as shooting ranges. The most common harmful substances causing the contamina- tion of soils are oil products, heavy metals, polyaromatic hydrocarbons, polychlorinated biphenyls, chlorophenols, and pesticides [1-3].

Oils may cause serious problems when spilled in soil or in water. A typical way of oils entering natural ecosystems is the breakage or leakage of hydraulic tubes or seals in machines working in forests (harvesters, forwarders), fields (agricultural tractors and excavators), or residential areas. Of course, leakages of oil containers, such as in the case of fuel oil and heating oil, are common in residential and industrial areas. There are also certain oils that are disposed in nature straight after they are being used, such as chain oils in connection with forestry and agriculture operations, or two-stroke engine oils. Oils used to preserve wood-based structures can also enter soil slowly during the lifespan of the wooden structure. The hazardousness of an oil product depends on the properties of the oil, what is the base of the oil type (mineral oil, synthetic oil, or natural oil), what are the additive types, as well as what is the concentration and viscosity of the oil, to mention a few. These characteristics have an effect on the biodegradation ability and toxicity of the oil, as well as on its 
aptitude to bioaccumulate or move in nature. On the other hand, the environment in which the oil spill occurs, and the magnitude of the spill finally determine the scope and seriousness of the environmental threat [4].

We have studied environmental effects of oils intensively during previous years by biodegradation measurements of various different types of oils in different environments [58 ]. We have carried out all the biodegradation evaluations using the same BOD OxiTop method used in this study. Firstly, the suitability of this method in terms of biodegradation measurements of oils in water was evaluated using forestry hydraulic oils as model oils [5]. This method seems to be accurate and precise for determining biodegradation abilities of oil products. Similar biodegradation experiments in water were carried out on certain forestry and agriculture chain oils [6], as well as on oils used to preserve wooden structures [7] in our subsequent studies. We have also compared the biodegradation potentials of the same types of chain oils and wood preservative oils as in the studies $[6,7]$ done in different forest soils. One of the aims of the study [8] was to find out if the respirometric BOD OxiTop device could be used in monitoring the biodegradation of oils in soil media. However, the study presented in [8] still raises questions: "How could the soils used be modified to make the effective biodegradation of oil products possible, and could this be done accurately and precisely?"; "Is an automatic respirometric method such as the BOD OxiTop method suitable for such studies?" The present article is a direct continuation for our previous studies and sets out to find out answers for the posed questions. The effect of the soil type and other environmental parameters on the biodegradation of chemicals in soils has also been studied intensively by other researchers during recent years [9-12].

\section{EXPERIMENTAL}

\subsection{Studied soils, model substances, and their analyses}

The soil mainly used as a measurement medium (soil 1) was collected from a forest area in the small municipality of Lumijoki (Finnish province, Northern Ostrobothnia, Finland) during February 2005. Certain preliminary experiments were also carried out on the soil used in our previous study [8]. This soil was labelled as soil 3s in that study [8], and the same labelling is also used in this study. However, because of the relatively long storage undergone by that soil sample, its microbial and mineral concentrations most likely underwent a degree of change from the original values given in [8]. This is why it was only used as a preliminary example of a mineralrich soil. Soil type, $\mathrm{pH}$, conductivity, and the amount of major nutrients were determined at Suomen Ympäristöpalvelu Oy, Oulu, Finland) which is a company specialized in soil fertility studies. The measurements were carried out whenever the soil properties ( $\mathrm{pH}$, nutrient content) were changed.

Conductivity and $\mathrm{pH}$ were measured from a $1: 2.5(\mathrm{v} / \mathrm{v})$ soil-water suspension with a Consort C $831 \mathrm{pH} / \mathrm{EC}$ analyzer. Concentrations of exchangeable calcium, potassium, magnesium, and easily soluble phosphorus were determined from a
$1: 10(\mathrm{v} / \mathrm{v})$ extract of a mixture of $0.5 \mathrm{M}$ acetic acid- $0.5 \mathrm{M}$ ammonium acetate. Concentrations of ammonium and nitrate nitrogen as well as exchangeable nitrogen were determined from a $1: 5(\mathrm{v} / \mathrm{v})$ soil $-2 \mathrm{M} \mathrm{KCl}$ suspension using a spectrophotometric method and the Foss-Tecator 5000 FIAstar flow injection analyser. Phosphorus was determined with a spectrophotometric molybdenum blue method using the Foss-Tecator 5000 FIAstar flow injection analyser. Calcium, potassium, and magnesium were measured with the Perkin Elmer AAnalyst 700 FAAS instrument. The bulk density of soil was measured using equipment with a measuring cylinder of $1 \mathrm{~L}$ and a weight of $650 \mathrm{~g}\left(8 \mathrm{~g} / \mathrm{cm}^{2}\right)$. The moisture content of the soil was determined by drying the soil in a heating chamber $\left(105^{\circ} \mathrm{C}\right)$ for 2 hours.

The model substances used in our studies were sodium benzoate, rapeseed oil used in different lubrication applications such as in drilling and other machine tool operations (marked as lubricating oil in the text hereafter), and rapeseed oil-based chain oil (marked as chain oil hereafter). Sodium benzoate is a typical, quickly biodegrading model substance recommended to be used in OECD guidelines. The carbon content of the oils was determined with a Perkin Elmer 2400 Series II CHNS/O analyzer (the so-called Dumas method) based on the combustion of the samples and the determination of carbon as carbon dioxide.

\subsection{Soil processing}

The effect of soil nutrient contents on the biodegradation rate was tested. Nutrient contents of the soil were increased with a complete fertilizer (Kemira fertilizer Y). Before fertilizer processing the soil was bisected. Fertilizer was dissolved in distilled water and then sprinkled into one soil sample. The other soil sample was sprinkled with distilled water in order to maintain a steady moisture content. After the fertilization, the soil was allowed to stabilize for about two weeks. Thereafter the $\mathrm{pH}$, conductivity, and nutrient contents were determined. The purpose was also to examine the effect of soil $\mathrm{pH}$ on the biodegradation process. Soil $\mathrm{pH}$ was adjusted to approximately 8.0 using a calcium carbonate $\left(\mathrm{CaCO}_{3}\right)$ solution. The basic solution was sprinkled into both soil samples in the same way as the fertilizer. Soil samples were allowed to stabilize for about two weeks in this case as well, prior to the soil property analysis.

\subsection{Biodegradability measurements}

A manometric respirometric test was carried out with the OxiTop Control system (WTW, Weilheim, Germany). The test is based on very accurate automatic pressure measurements in a closed bottle space, which has a constant temperature. A certain amount of oxygen is consumed during the biodegradation process of the organic matter. At the same time, the $\mathrm{CO}_{2}$ gas that is formed is removed from the gas space by means of an absorber $(\mathrm{NaOH})$. The instrument monitors the diminishing of pressure in the bottle. The information on diminished pressure can be used to evaluate the biodegradation of the samples. The soil was placed in an MG 1.0 bottle (WTW, Weilheim, Germany) suitable for 
TABLE 1: Influence of soil processing on the properties of sandy soil ( $\mathrm{ms}=$ mineral solution).

\begin{tabular}{|c|c|c|c|c|c|c|c|}
\hline Sample & $\mathrm{pH}$ & Conductivity $(\mathrm{cS} / \mathrm{cm})$ & $\mathrm{Ca}(\mathrm{mg} / \mathrm{L})$ & $\mathrm{P}(\mathrm{mg} / \mathrm{L})$ & $\mathrm{K}(\mathrm{mg} / \mathrm{L})$ & $\mathrm{Mg}(\mathrm{mg} / \mathrm{L})$ & $\mathrm{Ca} / \mathrm{Mg}$ \\
\hline Soil 1 & 6.1 & 0.2 & 150 & 2.4 & 36 & 56 & 2.70 \\
\hline Soil $1+\mathrm{ms}$ & 5.7 & 4.3 & 139 & 11.6 & 163 & 66 & 2.10 \\
\hline Soil $1+\mathrm{CaCO}_{3}$ & 8.0 & 0.9 & 1245 & 2.9 & 29 & 29 & 42.9 \\
\hline Soil $1+\mathrm{CaCO}_{3}+\mathrm{ms}$ & 7.7 & 5.3 & 822 & 19.7 & 186 & 52 & 15.8 \\
\hline
\end{tabular}

TABLE 2: Influence of soil processing on nitrogen concentrations of the sandy soil used ( $\mathrm{ms}=$ mineral solution).

\begin{tabular}{lccc}
\hline Sample & $\mathrm{NH}_{4}^{+}(\mathrm{mg} / \mathrm{L})$ & $\mathrm{NO}_{3}^{-}(\mathrm{mg} / \mathrm{L})$ & Exchangeable nitrogen $(\mathrm{mg} / \mathrm{L})$ \\
\hline Soil $1+\mathrm{CaCO}_{3}$ & 0.50 & 8.40 & 8.90 \\
Soil $1+\mathrm{CaCO}_{3}+\mathrm{ms}$ & 0.30 & 75.9 & 76.1 \\
\hline
\end{tabular}

soil measurements with a respirometric measuring device. Oil samples were added to soils in concentrations of about $1000 \mathrm{mg} / \mathrm{kg}$. A $50 \mathrm{~mL}$ beaker filled with a $1 \mathrm{M}$ sodium hydroxide solution was placed on the holder. The bottles were sealed tightly and the measurement heads were screwed onto the bottles. The bottles were held in an incubation cabinet at a temperature of $20.0 \pm 0.2^{\circ} \mathrm{C}$ for 30 days. A blank test was always conducted to determine soil respiration. The biodegradation measurements were always carried out at the same time to both soil samples (water addition, nutrient addition). The WTW BOD OxiTop device measures pressure in the bottle and the biological oxygen demand of the oil sample can be calculated using equations presented in more detail in our previous study [8]. The calculation of the BOD value is given in the following equations:

$$
\Delta m=\Delta p \cdot V_{\mathrm{fr}} \cdot M_{\mathrm{O}_{2}} /\left(R_{\mathrm{O}_{2}} \cdot T\right)
$$

in which $\Delta m$ is the amount of consumed oxygen $(g), \Delta p$ is the pressure change $(\mathrm{J} / \mathrm{L}), V_{\mathrm{fr}}$ is the free gas volume of the bottle $(\mathrm{L}), M_{\mathrm{O}_{2}}$ is the molecular weight of oxygen $(32 \mathrm{~g} / \mathrm{mol})$, $R_{\mathrm{O}_{2}}$ is $8.301 \mathrm{~J} / \mathrm{molK}$, and $T$ is $293.15 \mathrm{~K}$,

$$
\mathrm{BOD}[g / g]=\left(\Delta m-\Delta m_{\text {soil }}\right) / m_{\text {sample }}
$$

in which $\Delta m$ gives the amount of oxygen consumed by the soil-chemical mixture $(g), \Delta m_{\text {soil }}$ is the amount of soil respiration $(g)$, and $m_{\text {sample }}$ is the amount of oil weighed in the test. Therefore, the BOD value indicates the biological oxygen demand of the studied chemical.

The carbon content of the oils had to be known in order to calculate the theoretical oxygen demand ThOD $(g / g)$. For instance, the hydrogen and oxygen contents of the oil sample also affect the ThOD value. The studied oils are mixtures for which no molecular formula can be given. Thus every elemental concentration should be determined. However, oxygen cannot be determined using our elemental analyzer. Hence we decided to calculate the ThOD value using only the carbon content, because carbon is the main component in oils, and the influence of hydrogen and oxygen on the ThOD value is also partially opposite. Thus all our results are fully comparable with each other concerning the degree of biodegradation. The degree of biodegradation can thus be given as follows

Degree of biodegradation $=(\mathrm{BOD} / \mathrm{ThOD}) \cdot 100 \%$.

\section{RESULTS AND DISCUSSION}

\subsection{Soil properties}

Certain mineral concentrations and other properties of soil 1 before and after processing are indicated in Table 1 .

The soil that was used was sandy soil; its conductivity and concentrations of basic nutrients are low. The $\mathrm{pH}$ value is almost neutral. The fertilizer addition especially increased the phosphorus and potassium concentrations, as well as the conductivity of the soil. Addition of $\mathrm{CaCO}_{3}$ increased the $\mathrm{pH}$ value to 8.0 and clearly multiplied the calcium concentration at the same time. When mineral solution was added after the $\mathrm{pH}$ adjustment, a soil sample with high amounts of basic nutrients was obtained. The influence of the $\mathrm{pH}$ adjustment and the mineral addition on the concentrations of different types of nitrogen is given in Table 2.

Fertilizer addition increased the nitrate concentration, whereas the ammonium concentration was almost the same. However, the concentration of exchangeable nitrogen (the sum of ammonium and nitrate) increased over 8-fold. Considering the ability of the processed soil 1 to biodegrade chemicals, the options are quite good. There should be no limitations in terms of mineral, $\mathrm{pH}$, or moisture concerning biodegradation, because those levels were adjusted to more optimal values. The temperature in the measurements is also high $\left(20^{\circ} \mathrm{C}\right)$, corresponding to a typical mid-summer temperature in northern Finland. The only potential limitation could be the capacity of the soil microbes, that is, whether the soil will be able to adapt in order to be able to biodegrade the studied chemicals in this case oils.

\subsection{Preliminary tests using soil 3s}

Soil 3s was used only in the following preliminary test to evaluate the influence of soil processing on the ability of the soil to biodegrade chemicals. Soil $3 \mathrm{~s}$ was observed to be a very fertile forest soil in our previous study [8]. When the typical model substance, sodium benzoate, was biodegraded in soil 
$3 \mathrm{~s}$, the degree of biodegradation obtained was $85 \%$ in only 14 days [8]. The assumption was that its aptitude to biodegrade chemicals would probably be diminished due to its relatively long storage (over 6 months) in the laboratory. Soil $3 \mathrm{~s}$ was used as such, and with mineral addition to biodegrade sodium benzoate. Moisture was adjusted to a same value using water spraying. The observed degrees of biodegradation are presented in Figure 1.

As expected, the degree of biodegradation of sodium benzoate was smaller than the one obtained in the previous study [8] when using the same soil (3s). This time it took 30 days to obtain a BOD/ThOD value of $75 \%$, the 14 -day value was only $30 \%$, when earlier it was $85 \%$. This is obviously due to changes in the soil properties. However, mineral addition can enhance the aptitude of the soil to biodegrade chemicals. It especially seems to accelerate the starting phase (the 14-day value was now 72\%), and the stable phase (with BOD/ThOD value of $85.3 \%$ ) is reached in 20 days, whereas soil 3s without mineral addition did not reach the stable phase within the 30-day measurement period. Thus, the weak biodegradation potential of the soil can be improved significantly with mineral addition.

\subsection{Influence of mineral addition on biodegradation of oils}

The soil used in the experiments presented in Sections 3.3 and 3.4 is a sandy forest soil, the properties of which are described in Tables 1 and 2 in more detail. The biodegradation of sodium benzoate and chain oil in the soil were followed up by either including or omitting mineral additions. The moisture of the soil was always adjusted to a steady level. Results are presented in Figure 2.

Sodium benzoate biodegraded moderately without mineral addition; the observed BOD/ThOD value was $45.1 \%$ after thirty days; but when compared with our previous study [8], the observed BOD/ThOD value of sodium benzoate is significantly lower. Especially the starting phase of biodegradation, in which microbes adapt in order to be able to biodegrade sodium benzoate, seems to go on for a relatively long period in this soil (no biodegradation at all was observed during the first seven-day period). The addition of minerals enhanced the biodegradability potential of this soil significantly. The observed BOD/ThOD value of sodium benzoate was $76.2 \%$ after thirty days, and the stable phase was reached in 15 days. However, even with fertilizer addition, the ability of this soil to biodegrade sodium benzoate was not as good as the one of soil 3s. As presented in [8], the BOD/ThOD value of sodium benzoate in soil $3 \mathrm{~s}$ was as good as $85 \%$ in only 14 days, when the soil was fresh. The chain oil examined has also been studied earlier in [8]. Chain oil was marked rapeseed oil 1 in that study, and its degree of biodegradation was on average $43 \%$ after 14 days in soil 3 s, and the biodegradation was still effective after 14 days. However, the original soil 1 in this study was not at all suitable to biodegrade this type of chain oil; no biodegradation was observed during the measurement period of 30 days. Fertilization of the soil made biodegradation possible. BOD/ThOD value in this case was

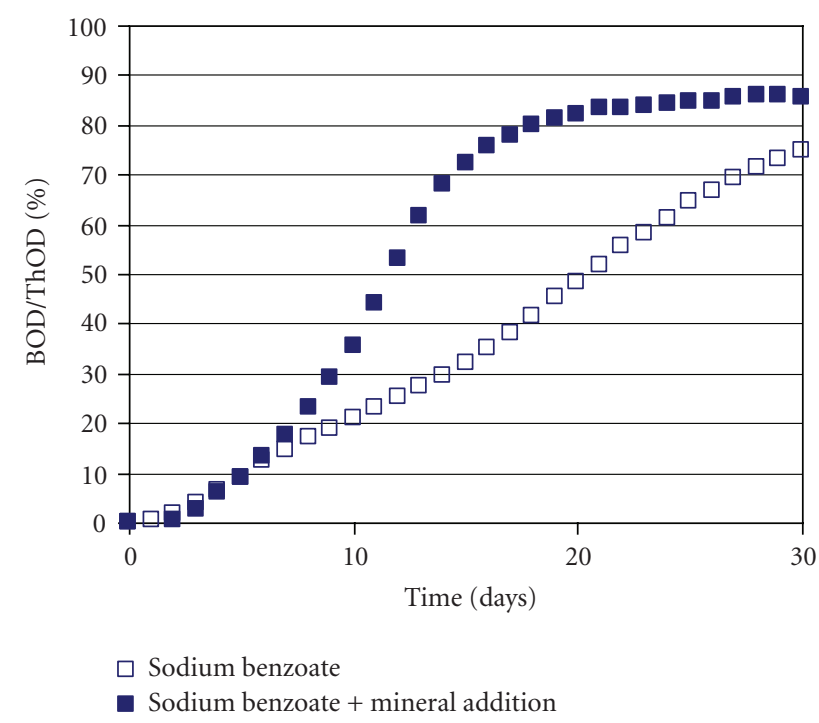

Figure 1: Influence of mineral addition on biodegradation of sodium benzoate in soil $3 \mathrm{~s}$ at $20^{\circ} \mathrm{C}$.

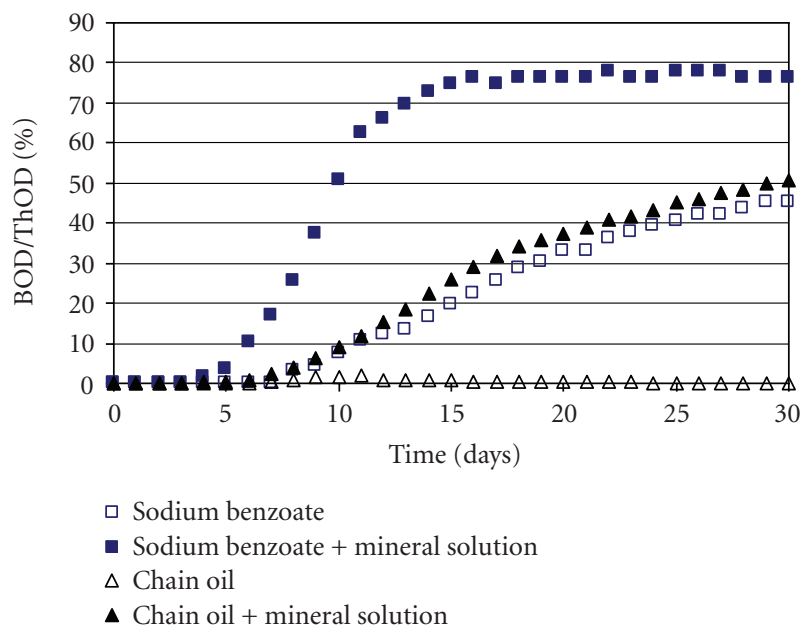

FIGURE 2: BOD/ThOD values of sodium benzoate and chain oil in fertilized and nonprocessed soil 1 at $20^{\circ} \mathrm{C}$.

$50.8 \%$ after 30 days and the 14 -day value was $22.3 \%$, which is about half of the values previously obtained for soil 3s [8].

A precision test for the biodegradability of chain oil in soil 1 was carried out exactly after one month had elapsed from the first measurement, as presented in Figure 2. Results of this precision test as well as results of the biodegradability of the rapeseed oil-based multipurpose lubricating oil not previously studied are presented in Figure 3.

Precision of the biodegradability measurement for the chain oil was not good in soil 1 whether there was a nutrient addition or not. Without nutrient addition chain oil 1 reached the $\mathrm{BOD} / \mathrm{ThOD}$ value of $1.8 \%$ in this test after 30 days, whereas the corresponding value in the previous test was $0 \%$. However, the observed value of $1.8 \%$ is almost nonsignificant in terms of biodegradability. When fertilization was used, the degree of biodegradation was $35.6 \%$ in the 


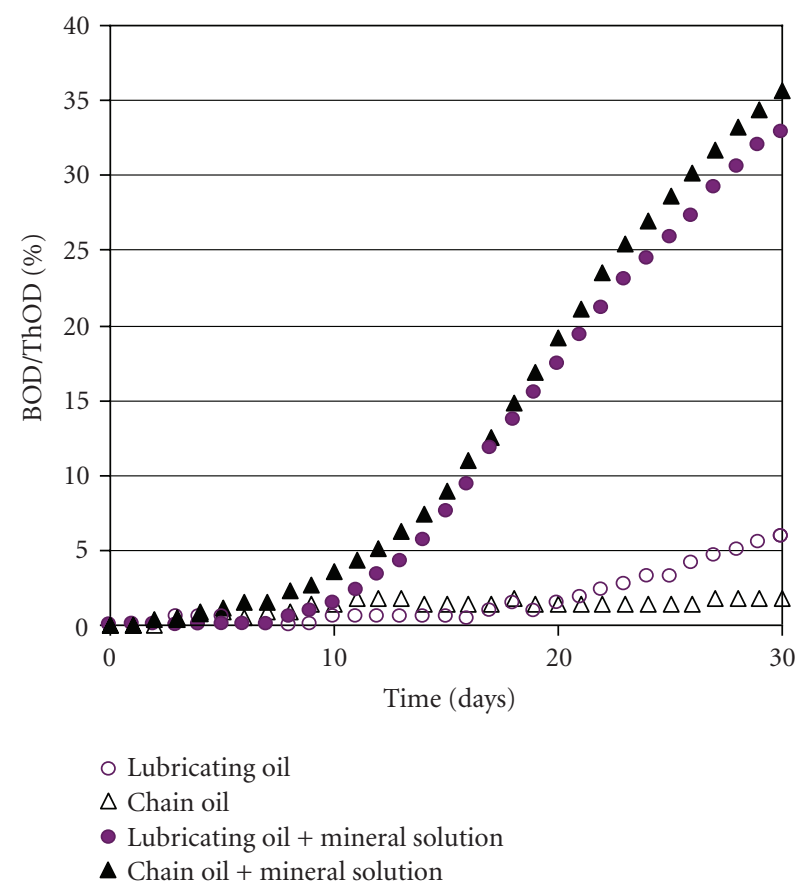

FIGURE 3: BOD/ThOD values of chain oil and lubricating oil in fertilized and nonprocessed soil 1 at $20^{\circ} \mathrm{C}$.

precision test, whereas the corresponding value in Figure 2 was $50.8 \%$. It seems that soil 1 is not as homogeneous as soil $3 \mathrm{~s}$, in which replication tests of both this chain oil and tall oil fatty acid (TOFA) produced significantly more precise results in a 14-day measurement period [8] than observed in this case. Perhaps, microbial activity of the sandy soil 1 depending on the used batch varies a lot, thus causing variations in the aptitude of the soil to biodegrade oils, because temperature, moisture, and mineral concentrations were adjusted to the same level. Lubricating oil biodegraded weakly in soil 1 without nutrient addition; the observed BOD/ThOD value was only $5.9 \%$ after 30 days. The nutrient addition raised the degree of biodegradation to a moderate value of $32.9 \%$ after 30 days.

\subsection{Influence of $\mathrm{pH}$ adjustment on biodegradation of oils}

The results of $\mathrm{pH}$ adjustment experiments are presented in Figure 4. The $\mathrm{pH}$ value of the soil was adjusted to approximately 8.0 using calcium carbonate. Experiments with and without nutrient addition were carried out. Moisture was always adjusted and kept at the same steady level.

When the $\mathrm{pH}$ of the soil was adjusted to 8.0, the lubricating oil reached a BOD/ThOD value of $9.5 \%$ in 30 days. This value is slightly higher than the one observed in the nonprocessed soil $(5.9 \%)$, but it is only less than one third of the corresponding BOD/ThOD value in the soil with mineral addition $(32.9 \%)$. The small enhancing influence on the $\mathrm{BOD} / \mathrm{ThOD}$ value is probably due to the increased calcium concentration in the soil, but the measurement accuracy also plays a significant role. When both the $\mathrm{pH}$ of the soil was ad-

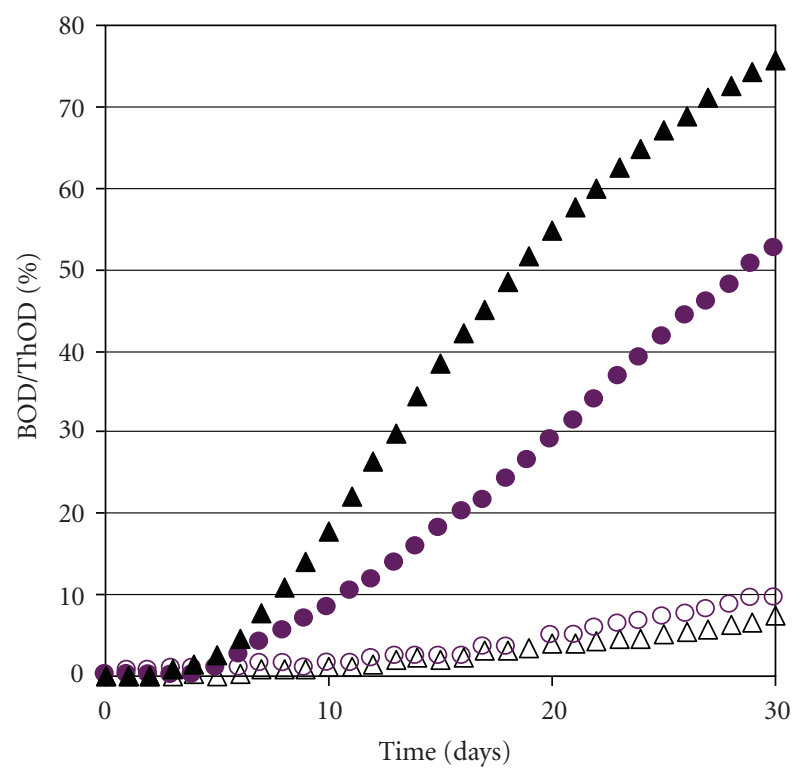

$\bigcirc$ Lubricating oil with $\mathrm{pH}$ adjustment

$\triangle$ Chain oil with $\mathrm{pH}$ adjustment

- Lubricating oil with pH adjustment and mineral addition

$\boldsymbol{\Delta}$ Chain oil with $\mathrm{pH}$ adjustment and mineral addition

FIgURE 4: The influence of soil $1 \mathrm{pH}$ adjustment on the biodegradability of lubricating oil and chain oil at $20^{\circ} \mathrm{C}$.

justed and extra minerals were added, the BOD/ThOD value of the lubricating oil increased significantly, being $52.3 \%$ after 30 days.

A similar behaviour was also observed when chain oil was studied. The lowest BOD/ThOD values (on average $0.9 \%$ in 30 days) were observed in the original soil, the $\mathrm{pH}$ adjustment increased the BOD/ThOD value slightly to $7.4 \%$, and mineral addition produced the average BOD/ThOD values of $43.2 \%$. Again when both the $\mathrm{pH}$ adjustment and the mineral addition were implemented, the BOD/ThOD values observed were significantly enhanced, upto $75.8 \%$ after 30 days. One important compound influence of the $\mathrm{pH}$ adjustment and mineral addition on the biodegradation is that biodegradation reactions seem to start at an earlier stage than when soil is not processed.

Precision of the biodegradability measurements of the lubricating oil was examined in soil 1, when extra minerals were added, and the $\mathrm{pH}$ was adjusted to approximately 8.0 (the exact $\mathrm{pH}$ value was 7.7). The time period between the two experiments was about two months. Results are presented in Figure 5.

When the precision test was carried out for chain oil in soil 1 with mineral addition, the results were not very promising. However, when lubricating oil was tested in soil with an adjusted $\mathrm{pH}$ and added extra minerals, the results were completely different. The degrees of biodegradation observed were 52.3 and $51.4 \%$ after 30 days, and the behaviour of both samples seems to be quite similar during the measurement period. Thus the precision of the BOD OxiTop method in soil measurements seems to be accurate after all. 


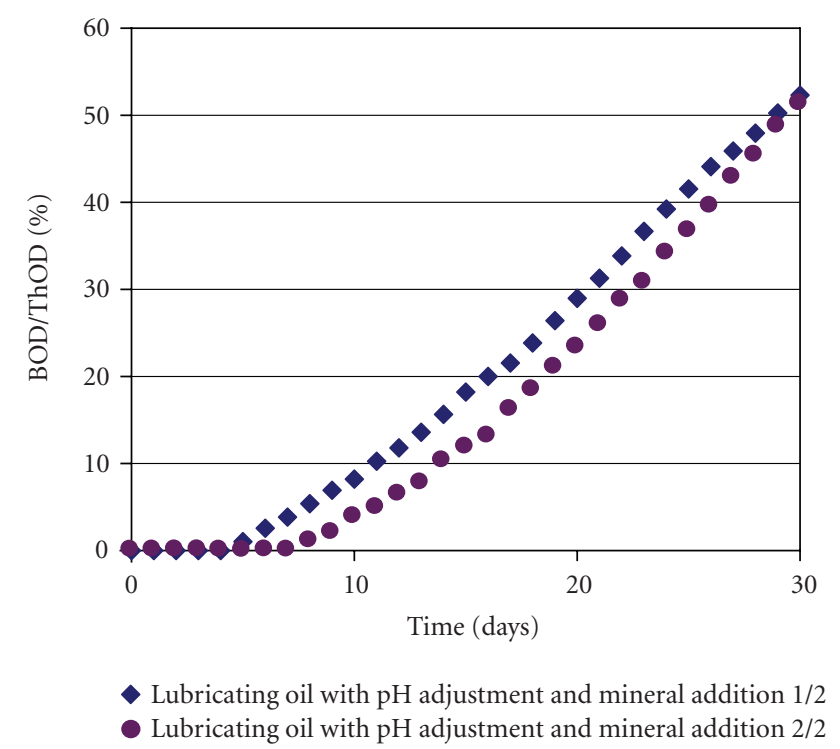

Figure 5: Precision test of the biodegradability measurement of lubricating oil in soil 1 at $20^{\circ} \mathrm{C}$.

This supports the results observed in our previous study [8]. The soil just has to be homogeneous enough in order for precise results to be achieved.

All in all it was observed in our previous study [8] that when the soil used to biodegrade oils is fertile enough and has suitable microbial concentrations, it can be used as such without additional processing, a situation which enables fast biodegradability. Naturally, was some degree of oil spillage to occur in an area with such a soil, an environmental threat does exist. However, the consequences may be relatively minor due to fast biodegradation reactions. As seen in [8] as well as in this study, if the soil is not fertile enough, biodegradation is either very slow or not even observable. Nevertheless, even an infertile soil unsuitable for oil biodegradation can be enhanced using $\mathrm{pH}$, moisture, and mineral adjustments. Microbes in the soil usually adapt to biodegrade oils, and microbial seeding can also be used if necessary. Hence, in the case of contamination with oil hydrocarbons, soil remediation is possible by using natural, inexpensive ways, and expensive remediation techniques are not necessarily required. It should be considered, however, that we have mainly studied rapidly biodegrading oils, and the emphasis of our studies warrants to be shifted in the direction of more harmful mineral oil products.

\section{CONCLUSIONS}

The biodegradation of certain biofuels were studied in infertile forest soil using the manometric respirometric BOD OxiTop method. The possibilities of enhancing oil biodegradation were also clarified. The BOD OxiTop method was observed to be a suitable tool to monitor oil biodegradation reactions in the soil. Thus it could also be used when, for example,. the bioremediation of oil-contaminated soils is studied. The combined effect of suitable mineral addition and $\mathrm{pH}$ adjustment on soil enhanced the biodegradation of these oils significantly. Mineral addition alone can increase $\mathrm{BOD} / \mathrm{ThOD}$ values of oils in the soil relatively much, whereas $\mathrm{pH}$ adjustment alone does not improve biodegradation very much. One important benefit in the use of mineral addition and $\mathrm{pH}$ adjustment besides improved biodegradation is that the soil can be made more homogeneous and the measurements will be significantly more precise. In the future, it would be beneficial to study more harmful oil products such as mineral oils in soil. It would also be interesting to determine the optimal amount and types of microbes for oil biodegradation.

\section{ACKNOWLEDGMENTS}

The authors would like to thank Suomen Ympäristöpalvelu Oy for the nutrient analyses of the soil used and Ilkka Välimäki for discussions regarding soil fertility, as well as Mrs. Hanna Prokkola for certain measurements. A special word of thank you goes also to Ilari Sohlo for proofreading this study.

\section{REFERENCES}

[1] J. Sarkkila, U.-M. Mroueh, and H. Leino-Forsman, Pilaantuneen Maan Kunnostaminen Ja Laadunvarmistus, Ympäristöopas 110, Suomen ympäristökeskus, Helsinki, Finland, 2004.

[2] Ministry of the Environment in Finland, Saastuneet MaaAlueet Ja Niiden Käsittely Suomessa, Loppuraportti, Muistio 5, Ympäristöministeriön, Helsinki, Finland, 1994.

[3] Commission of the European Communities, "Proposal for a directive of the European Parliament and of the Council establishing a framework for the protection of soil and amending Directive 2004/35/EC," 2006.

[4] W. J. Bartz, "Lubricants and the environment," Tribology International, vol. 31, no. 1-3, pp. 35-47, 1998.

[5] T. Kuokkanen, P. Vähäoja, I. Välimäki, and R. Lauhanen, "Suitability of the respirometric BOD Oxitop method for determining the biodegradability of oils in ground water using forestry hydraulic oils as model compounds," International Journal of Environmental Analytical Chemistry, vol. 84, no. 9, pp. 677-689, 2004.

[6] P. Vähäoja, T. Kuokkanen, I. Välimäki, S. Vuoti, and P. Perämäki, "Biodegradabilities of some chain oils in groundwater as determined by the respirometric BOD OxiTop method," Analytical and Bioanalytical Chemistry, vol. 381, no. 2, pp. 445-450, 2005.

[7] P. Vähäoja, P. Piltonen, A. Hyvönen, J. Niinimäki, J. Jalonen, and T. Kuokkanen, "Biodegradability studies of certain wood preservatives in groundwater as determined by the respirometric BOD OxiTop method," Water, Air, and Soil Pollution, vol. 165, no. 1-4, pp. 313-324, 2005.

[8] P. Vähäoja, K. Roppola, I. Välimäki, and T. Kuokkanen, "Studies of biodegradability of certain oils in forest soil as determined by the respirometric BOD OxiTop method," International Journal of Environmental Analytical Chemistry, vol. 85, no. 14, pp. 1065-1073, 2005.

[9] J. Salminen, "Natural attenuation of anthropogenic organic compounds in boreal soil and groundwater," Doctoral thesis, Tampere University of Technology, Tampere, Finland, 2005. 
[10] A. G. Rike, K. B. Haugen, M. Børresen, B. Engene, and P. Kolstad, "In situ biodegradation of petroleum hydrocarbons in frozen arctic soils," Cold Regions Science and Technology, vol. 37, no. 2, pp. 97-120, 2003.

[11] W. W. Mohn and G. R. Stewart, "Limiting factors for hydrocarbon biodegradation at low temperature in Arctic soils," Soil Biology \& Biochemistry, vol. 32, no. 8-9, pp. 1161-1172, 2000.

[12] S.-H. Lee, S. Lee, D.-Y. Kim, and J.-G. Kim, "Degradation characteristics of waste lubricants under different nutrient conditions," Journal of Hazardous Materials, vol. 143, no. 1-2, pp. 65-72, 2007. 


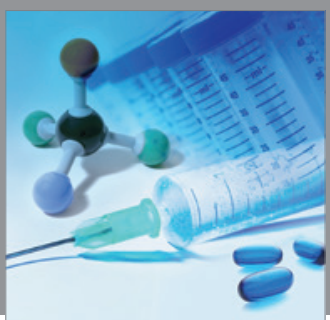

International Journal of

Medicinal Chemistry

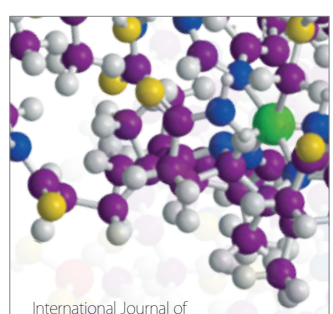

Carbohydrate Chemistry

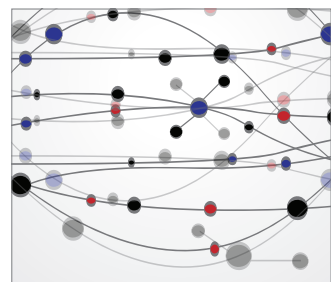

The Scientific World Journal
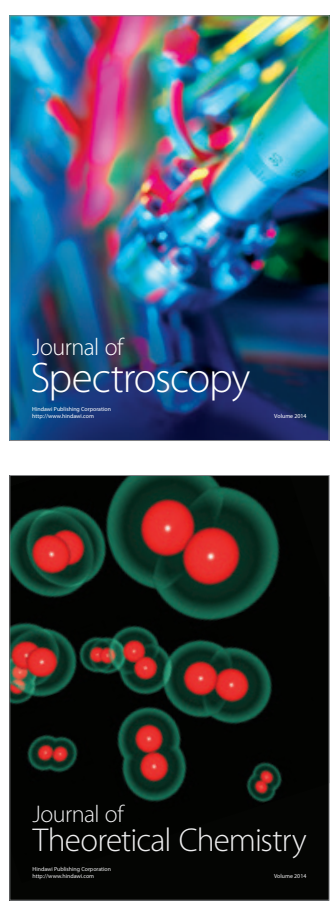
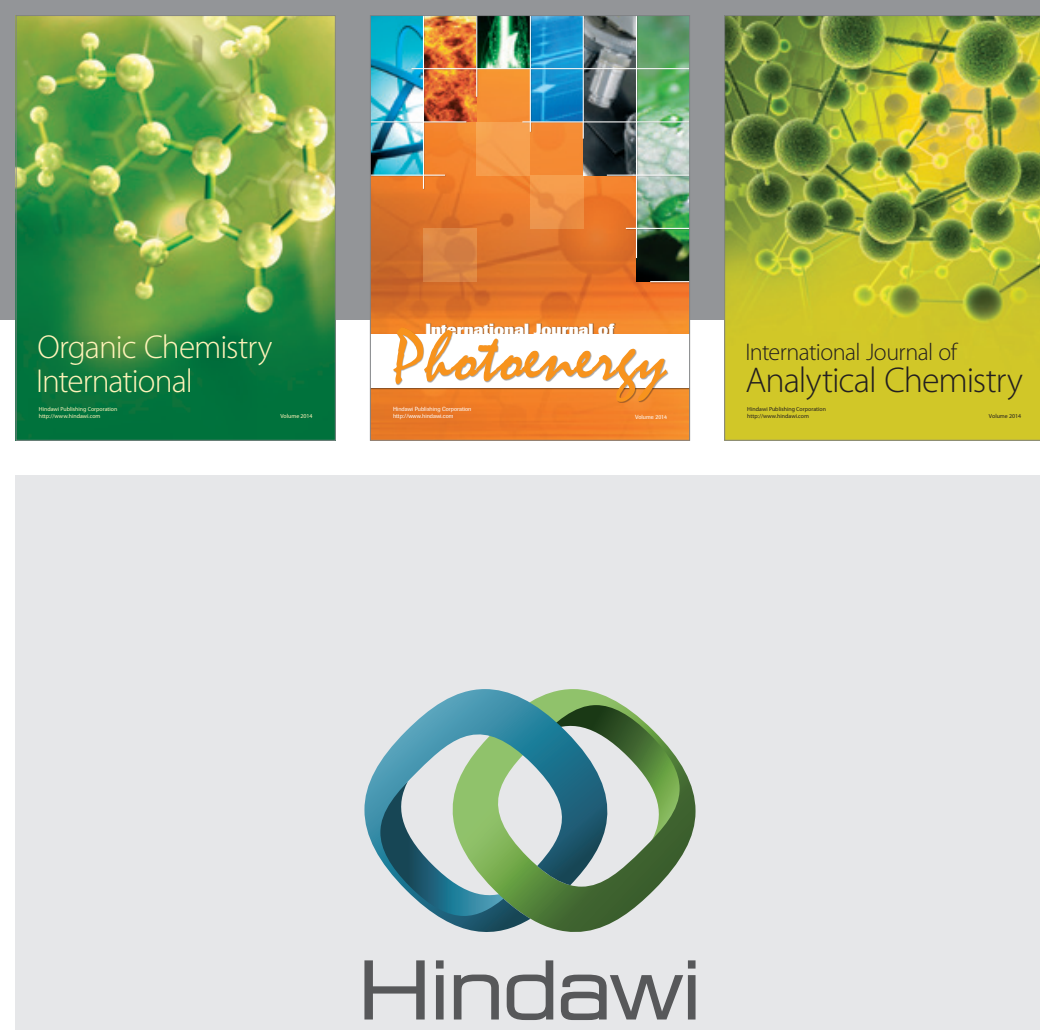

Submit your manuscripts at

http://www.hindawi.com
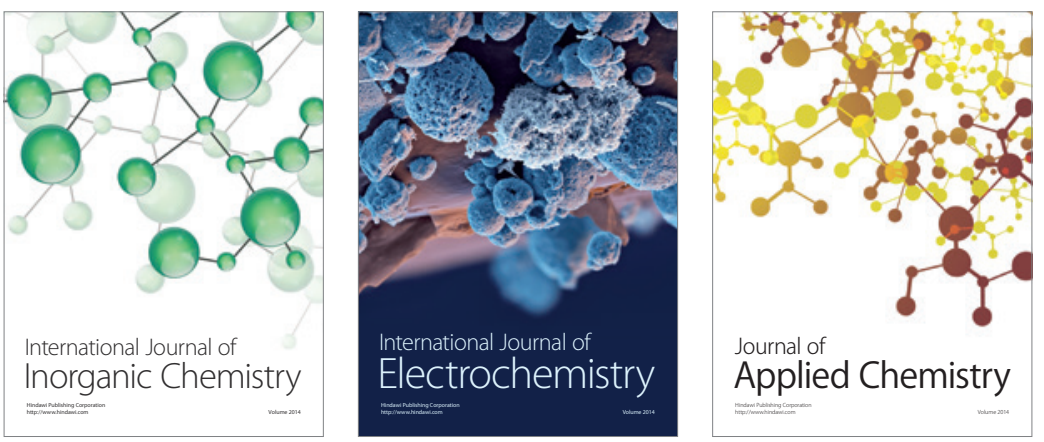

Journal of

Applied Chemistry
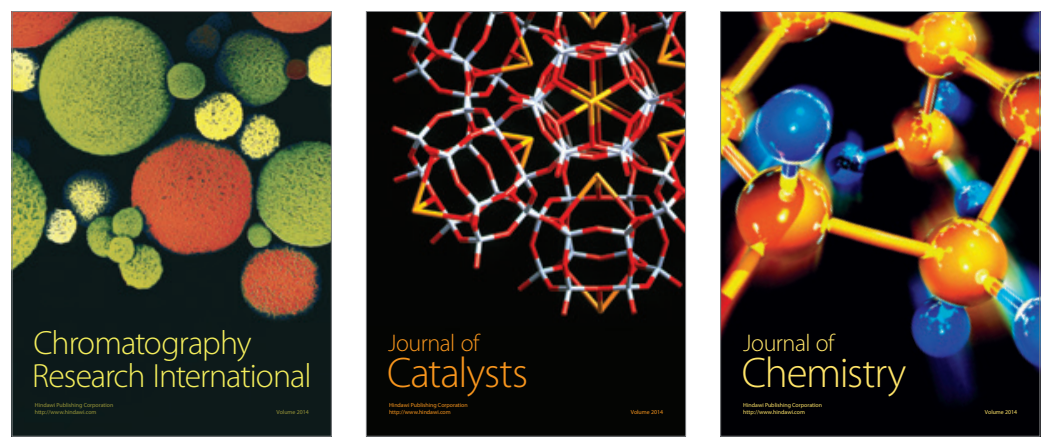
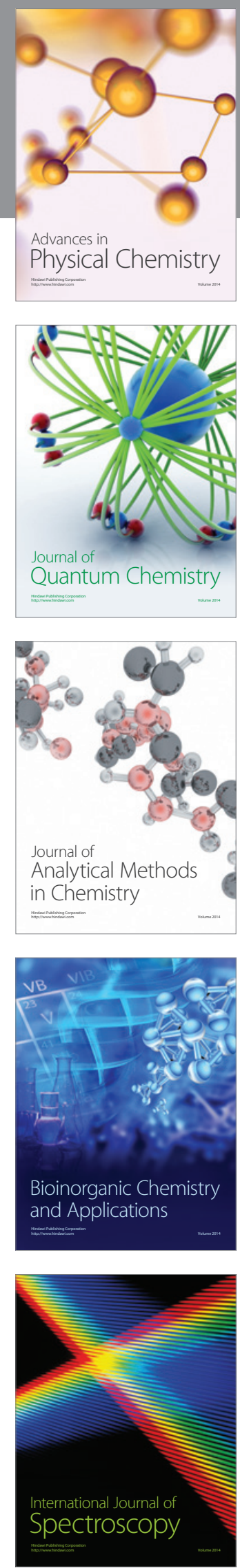